\title{
The effects of corporate social responsibility on entry
}

\author{
Luciano Fanti ${ }^{1} \cdot$ Domenico Buccella ${ }^{2}$
}

Received: 20 November 2015/Revised: 4 January 2016/Accepted: 23 January 2016/ Published online: 17 February 2016

(C) The Author(s) 2016. This article is published with open access at Springerlink.com

\begin{abstract}
This paper investigates entry decisions in industries where firms follow Corporate Social Responsibility (CSR) behaviours. Provided that the market is sufficiently large, the key result is that the adoption of CSR rules acts, loosely speaking, as an entry barrier in the industry because the incumbent imposes a "penalisation" on the potential entrant's profits which is more harmful the larger the social concern is. As regards social welfare, two interesting results appear. For relatively high fixed costs, a welfare reducing entry may happen; however, low levels of the social concern may reduce the likelihood of a welfare reducing entry, in line with the belief that CSR is pro-consumers. On the other hand, in sharp contrast with this belief, for a sufficiently high level of social concern, entry is deterred when duopoly is welfare improving: taking care about consumers' welfare by firm brings upon a damage for consumers.
\end{abstract}

Keywords CSR $\cdot$ Duopoly $\cdot$ Profitability $\cdot$ Social welfare

JEL Classification $\quad$ D21 $\cdot$ L13 $\cdot$ L14 $\cdot$ M14

Domenico Buccella

buccella@kozminski.edu.pl

Luciano Fanti

lfanti@ec.unipi.it

1 Department of Economics and Management, University of Pisa, Via Cosimo Ridolfi, 10, I, 56124 Pisa, PI, Italy

2 Department of Economics, Kozminski University, Jagełłonska Street, 57/59, 03301 Warsaw, Poland 


\section{Introduction}

The widely observed adoption of firms' corporate social responsibility (CSR) behaviours has recently, and more frequently raised the debate among scholars (e.g. (Baron 2001, 2009; Benabou and Tirole 2010; Goering 2007, 2008; Jensen 2001; Lambertini and Tampieri 2010). Actually, according to KPMG (2011, 2013), CSR behaviours are undeniably a prevailing global business practice: in 2013, $71 \%$ of 4100 companies surveyed in 41 countries have reported the realisation of CSR activities. This figure represents an increase of $7 \%$ points since 2011, when $64 \%$ of the companies surveyed issued CRS reports.

The conventional wisdom as regards the welfare effects of the introduction of CSR rules in the firms' behaviour argues that, in general, increasing social concern or responsibility of the firms is necessarily welfare improving. For example, this is the view prevailing in the European Union and between most scholars ${ }^{1}$.

In this paper we show that this conventional wisdom does not necessarily hold true, since the effects of adopting CSR behaviours on social welfare may be also dependent upon the long run effects of such adoption on the market structure and the shape of competition.

In particular, provided that the market size is adequately large, entry can be more easily deterred by the existence of social concerns in the industry, and the higher the social concern the less likely is the entry. On the other hand, when the social concern is relatively high and the consumers and social welfare would be higher under duopoly, then such a choice, by impeding entry, results to be welfare damaging, despite it aims to protect the consumers' interests. These results are in contrast to the conventional wisdom.

Therefore, these findings may be important for the current policy debate on firms' social concern and of particular interest for antitrust and competition policies.

The rest of this paper is structured as follows. Section 2 introduces the monopoly and duopoly models with CSR rules and the analysis discusses the issue of entry in this context. The last section concludes our findings.

\section{The model}

We begin developing the monopoly model. The inverse demand function is:

$$
p=a-q
$$

where $p$ and $q$ denote the price and the quantity of the goods produced, respectively. To focus on the effects of the adoption of CSR rules in this industry, we consider that the firm's marginal cost is zero. Given (1), the monopolist's profit function is:

$$
\pi=(a-q) q .
$$

\footnotetext{
${ }^{1}$ For instance, the belief that social concern is welfare improving is evident in the content of the European Union Commission's Green Paper (European Commission 2001), "Promoting a European framework for corporate social responsibility", and in Frank (2003) who argues that social concern increases social welfare by enhancing the "common good"
} 
Following the recent established literature (e.g. Goering 2007, 2008; Lambertini and Tampieri 2010), we define the inclusion of a fraction of the market consumer surplus $k$ as the firm's "social concern" or care for consumer outcomes in the market. As a consequence, the CSR firm's objective function may be specified as a simple parameterized combination of profits and consumer surplus. Thus, the CSR firm objective function $(W)$ is:

$$
W=\pi+k C S=(a-q) q+k \frac{q^{2}}{2}
$$

where $k \in[0,1]$ denotes the weight that the CSR firm assigns to consumer surplus. ${ }^{2}$

The analysis is carried out usual through the maximisation of (3) with respect to the quantity. The equilibrium output is:

$$
q^{M}=\frac{a}{2-k}
$$

where the upper script $M$ stands for "monopoly". After substitution of (4) into (2), the monopoly profits are

$$
\pi^{M}=\frac{a^{2}(1-k)}{(2-k)^{2}}
$$

with $\frac{\partial \pi^{M}}{\partial k}<0$ : an increase in the monopolist's social concern decreases profitability.

Consider now the case of entry. We assume that the stakeholders participation in governance applies on market decisions while the company strategy (such as the entry decision) is beyond their scope. Put differently, we assume that the stakeholders exert "pressure" as regards the firm's objective; however, the company's strategic choices are made by private owners. This hypothesis appears to be consistent with the empirical study of Spitzeck and Hansen (2010), who find that the stakeholder engagement mechanism is mainly restricted to "dialogue and issues" advisory. Moreover, in the large majority of the companies included in their survey, the authors have found that stakeholders have been consulted on managerial issues such as reporting, identification of key performance indicators, risk management, spotting opportunities as well as reputation management. Those subjects pertain to "the company's current approach towards relevant issues for stakeholders and do not involve any input on company strategy or business development" (Spitzeck and Hansen 2010).

We define firm 1 as the incumbent and firm 2 the potential entrant. In duopoly, the inverse market demand function becomes:

$$
p=a-q_{i}-q_{j}
$$

\footnotetext{
${ }^{2}$ Goering $(2007,2008)$ attributes this objective function also to the Non-profit organizations (NPO) which compete in commercial markets, for instance in sectors including University bookstores (Schiff and Weisbrod 1991), water utility, rail track maintenance company, private air-traffic control organization (Bennett et al. 2003) and even in the high-tech markets (Benz 2005). Therefore commercial NPOs selling their output and services, which provide them revenue, may be considered CSR firms.
} 
where $q_{i}$ and $q_{j}$ are the firms' output levels for $i, j=1,2$ and $i \neq j$. The profit functions are

$$
\begin{gathered}
\pi_{1}=\left(a-q_{1}-q_{2}\right) q_{1} \\
\pi_{2}=\left(a-q_{1}-q_{2}\right) q_{2}-E
\end{gathered}
$$

for the incumbent and the entrant, respectively. We assume, for simplicity, that both incumbent and entrant follow the same CSR rules. ${ }^{3}$ Thus, the firms' CSR objective function $(W)$ are:

$$
\begin{gathered}
W_{1}=\pi_{1}+k C S=\left(a-q_{1}-q_{2}\right) q_{1}+k \frac{\left(q_{1}+q_{2}\right)^{2}}{2} \\
W_{2}=\pi_{2}+k C S=\left(a-q_{1}-q_{2}\right) q_{2}+k \frac{\left(q_{1}+q_{2}\right)^{2}}{2}-E
\end{gathered}
$$

for the incumbent and the entrant, respectively. The term $E$ represents an exogenous fixed cost the entrant faces.

Given (9) and (10), the firms' maximization problem and the solution of the FOCs' system lead to the firms' output decision:

$$
q^{D}=\frac{a}{3-2 k}
$$

where the upper script $D$ stands for "duopoly". Substituting (11) into the firms' profit functions, we get the duopoly profits in equilibrium

$$
\pi^{D}=\frac{a^{2}(1-2 k)}{(3-2 k)^{2}}-E
$$

with $\frac{\partial \pi^{D}}{\partial k}<0$. Let us briefly discuss the results. From (12), if $E=0$ (no entry costs) the satisfaction of the non-negativity constraints on profits $\pi^{D} \geq 0$ requires that $k \leq k^{\max }=\frac{1}{2}$. However, if $E>0$ the potential entrant decides to enter if

$$
k \leq k^{*}=\frac{a \sqrt{a^{2}-8 E}-a^{2}+6 E}{E}<k^{\max } .
$$

That is, the firm's interest for the consumer's welfare has not to be too high. To ensure a positive value of $k^{*}$, Eq. (13) implies that

$$
E \leq E^{*}=\frac{a^{2}}{9}
$$

In fact, in the case of $E>E^{*}$, the fixed costs become excessively high for the potential competitor because these imply that whatever positive value of $k$ blocks

\footnotetext{
3 Although here exogenously given, note that this assumption is robust because it can be easily verified that, in a SPNE, both duopoly firms select to adopt the same CSR rules (for an analysis of SPNE in a duopoly without entry, see Fanti and Buccella (2015).
} 


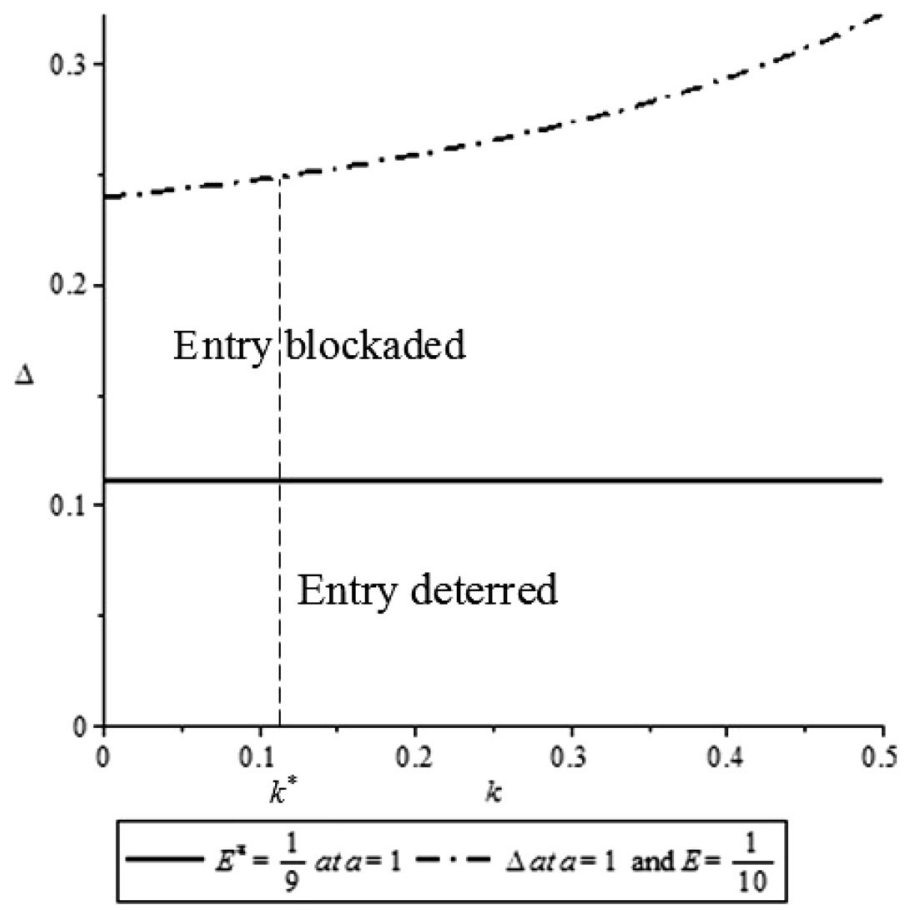

Fig. 1 Graphical representation of Result 1 for $a=1$ and $E=\frac{1}{10}$, leading to $k^{*}=.118$

entry. Therefore, CSR rules need a sufficiently large market to be adopted as an entry barrier. Defining $\Delta=\pi^{M}-\left(\pi^{D}-E\right)=-\frac{a^{2}\left(9 k+2 k^{3}-7 k^{2}-5\right)}{(3-2 k)^{2}(2-k)^{2}}-E$, the following Result holds.

Result 1: (1) If $E>E^{*}$, entry is blockaded; (2) if $E \leq E^{*}$ : (a) there is always a value of the social concern $k^{P} \in\left(k^{*}, k^{\mathrm{max}}\right]$ that deters entry; and (b) if $k \in\left[0, k^{*}\right]$, the presence of social concerns may hamper entry; that is, the higher $k$ the less likely entry.

Proof Part (1) and (2) (a) directly derive from the above discussion. Part (2) (b) straightforwardly follows from $\frac{\partial \Delta}{\partial k}>0$.

Figure 1 graphically depicts Result 1 for the values of $a=1$ and $E=\frac{1}{10}<E^{*}=\frac{1}{9}$, and shows that, for $k \rightarrow \frac{1}{2}$, the profit differential $\Delta$ increases monotonically.

Intuitively, CSR rules tend to act, loosely speaking, as an entry barrier in the industry, because their adoption decreases the entrant firm's profitability. Therefore, the incumbent may strategically follow CSR behaviours to inflict a profit "penalisation" to the potential entrant which is more damaging the larger the social concern is. ${ }^{4}$

\footnotetext{
${ }^{4}$ Formally, $\left|\frac{\partial \pi^{M}}{\partial k}\right|>\left|\frac{\partial \pi^{D}}{\partial k}\right|$.
} 


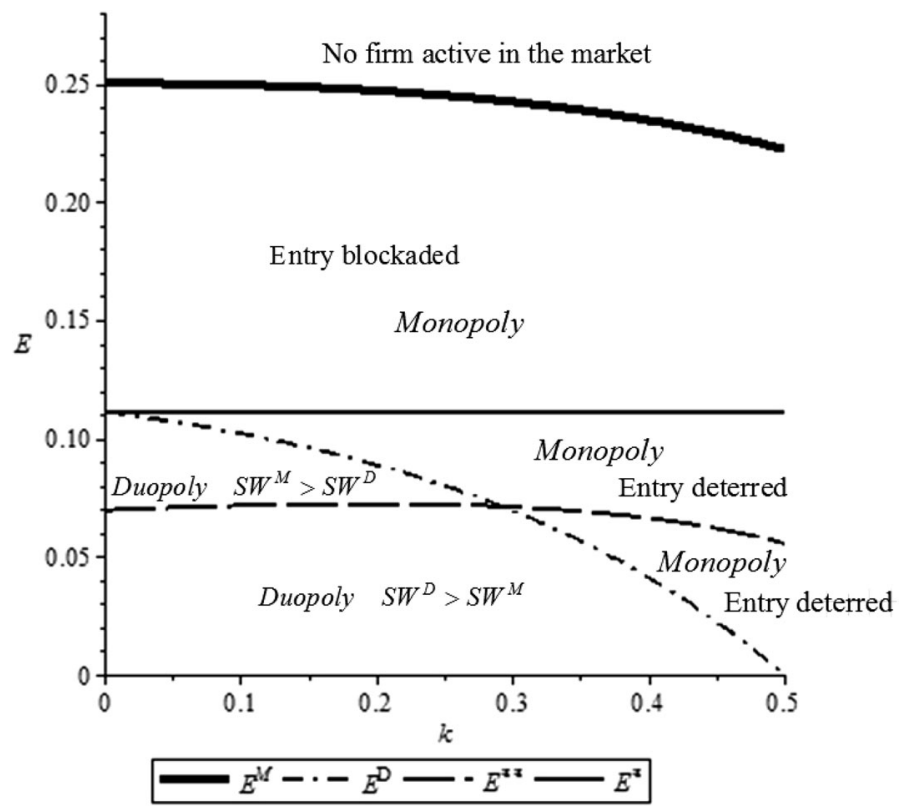

Fig. 2 Welfare effects of entry. The graph is depicted for $a=1$

Let us discuss the welfare effects of entry. The social welfare under monopoly is given by $S W^{M}=\pi^{M}+C S$, while under duopoly is $S W^{D}=\pi_{1}^{D}+\pi_{2}^{D}+C S-E$; therefore, the social welfare differential between monopoly and duopoly is

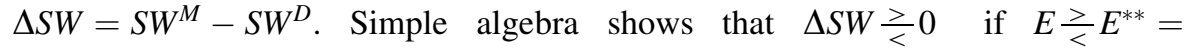
$\frac{4 k^{2}-10 k+5}{2(2-k)^{2}(3-2 k)^{2}}$. From (5) it is immediately derived that for $E>E^{M}=\frac{1-k}{(2-k)^{2}}, \pi^{M}<0$ and no firms are active in the market. Result 1 directly reveals that for $E^{M} \geq E>E^{*}$, entry is blockaded and monopoly is the industry structure. From (12) it is obtained that $E^{*} \geq E>E^{D}=\frac{1-2 k}{(3-2 k)^{2}}$, and the incumbent may deter entry. However, if $E^{D}>E \geq E^{* *}$, entry occurs, the market structure moves from monopoly to duopoly but social welfare under monopoly is higher than under duopoly, i.e. a welfare reducing entry takes place. On the other hand, if $E^{*}>E \geq E^{* *}$, entry is deterred and this guarantees a welfare outcome superior to duopoly. Finally, for $E^{* *}>E \geq 0$, the social welfare under duopoly is higher than under monopoly; however, if $E^{* *}>E \geq E^{D}$, that is provided that $k \geq .29$, the monopolist is able to prevent entry implying a social welfare damage (Fig. 2).

When the market structure is endogenous, an element commonly perceived to have a positive impact on social welfare such as consumers' care (the social concern) may turn out to be, when sufficiently high, welfare detrimental. 


\section{Conclusions}

This paper has investigated entry decisions in industries where firms follow corporate social responsibility (CSR) behaviours.

The key result is that, if the fixed costs are adequately low, which implies that the market size has to be large enough, the incumbent may always deter entry adopting CSR rules. The rationale for this result is that the incumbent imposes a "penalisation" on the potential entrant, i.e. it reduces its profits, which is more detrimental the larger the social concern is. With regard to social welfare, two interesting results arise: (1) for relatively high fixed costs, a welfare reducing entry can take place; however, low levels of the social concern may reduce the possibility of a welfare reducing entry, in line with the belief that CSR acts in favour of the consumers; and (2) in contrast with this belief, for combinations of a sufficiently high level of social concern and low fixed costs, the incumbent can deter entry when duopoly is welfare improving: the monopolist's care about consumers' welfare brings upon a damage for consumers.

These findings contribute to the increasing policy debate on firms' social concern, showing a so far not explored effect of such concerns on the long run market structure and, consequently, on the overall social welfare. This has evident implications for antitrust and competition policies.

Acknowledgments We are extremely grateful to an Associate Editor of this Journal and a referee for comments and suggestions that have substantially contributed to improve the quality of this paper. Usual disclaimers apply.

\section{Compliance with ethical standards}

Funding This study was not funded by any Institution.

Conflict of interest The authors declare that they have no conflict of interest.

Open Access This article is distributed under the terms of the Creative Commons Attribution 4.0 International License (http://creativecommons.org/licenses/by/4.0/), which permits unrestricted use, distribution, and reproduction in any medium, provided you give appropriate credit to the original author(s) and the source, provide a link to the Creative Commons license, and indicate if changes were made.

\section{References}

Baron, D. (2001). Private politics, corporate social responsibility, and integrated strategy. Journal of Economics and Management Strategy, 10, 7-45.

Baron, D. P. (2009). A positive theory of moral management, social pressure, and corporate social performance. Journal of Economics and Management Strategy, 18, 7-43.

Benabou, R., \& Tirole, J. (2010). Individual and corporate social responsibility. Economica, 77, 1-19.

Bennett, J., Iossa, E., \& Legrenzi, G. (2003). The role of commercial non-profit organizations in the provision of public services. Oxford Review of Economic Policy, 19, 335-347.

Benz, M. (2005). Not for profit, but for satisfaction? Evidence on worker well-being in non-profit firms. Kyklos, 58, 155-176. 
European Commission (2001). Promoting a European framework for corporate social responsibility. Green Paper, Office for Official Publications of the European Communities, Luxembourg.

Fanti, L., \& Buccella, D. (2015). Corporate social responsibility in a game-theoretic context. Mimeo.

Frank, R. (2003). What price the moral high ground? Ethical dilemmas in competitive environments. Princeton: Princeton University Press.

Goering, G.E. (2007). The strategic use of managerial incentives in a non-profit firm mixed duopoly. Managerial and Decision Economics, 28, 83-91.

Goering, G.E. (2008). Welfare impacts of a non-profit firm in mixed commercial markets. Economic Systems, 32(2008), 326-334.

Jensen, M.C. (2001). Value maximization, stakeholder theory, and the corporate objective function. Journal of Applied Corporation Finance, 14(3), 8-21.

KPMG (2011). KPMG Survey of Corporate responsibility reporting 2013. Available online at https:// www.kpmg.com/PT/pt/IssuesAndInsights/Documents/corporate-responsibility2011.pdf.

KPMG (2013). KPMG Survey of Corporate responsibility reporting 2013. Available online at https:// assets.kpmg.com/content/dam/kpmg/pdf/2015/08/kpmg-survey-of-corporate-responsibility-reporting2013.pdf.

Lambertini, L., \& Tampieri, A. (2010). Corporate Social Responsibility in a Mixed Oligopoly. Department of Economics, University of Bologna, Working paper 723.

Schiff, J., \& Weisbrod, B. (1991). Competition between for-profit and nonprofit organizations in commercial markets. Annals of Public and Cooperative Economics, 62, 619-639.

Spitzeck, H., \& Hansen, E.G. (2010). Stakeholder governance: How stakeholders influence corporate decision making. Corporate Governance: The International Journal of Business in Society, 10(4), 378-391. 